American Journal of Applied Sciences 2 (9): 1274-1278, 2005

ISSN 1546-9239

(c) 2005 Science Publications

\title{
An HIV/AIDS Model with Variable Force of Infection and its Application to the Epidemic in Uganda
}

\author{
Flugentius Baryarama, Joseph Y.T. Mugisha and Livingstone S. Luboobi \\ Department of Mathematics, Makerere University, Box 7062, Kampala, Uganda
}

\begin{abstract}
An HIV/AIDS model is formulated with variable force of infection for the adult population. Its actions are reduced to a prevalence equation that is a non-logistic equation whose explicit solution is derived. The implications of applying the solution to the evolution of the HIV/AIDS epidemic are discussed with respect to the positive boundedness of the coefficients. Prevalence projections are presented for various initial prevalences and behavior change parameters. The main finding is that in settings with high recruitment rates, the HIV epidemic reaches peak prevalence (and thereafter start declining) when the rate of new infections is still higher than the rate of removal of those infected with HIV.
\end{abstract}

Key words: HIV/AIDS model, prevalence rates, force of infection, adult population

\section{INTRODUCTION}

Behavior change is recognized as the major way of combating the spread of the HIV/AIDS epidemic given that there is no cure or vaccine for the virus. Accordingly from the early nineteen nineties, modeling of HIV/AIDS was directed towards incorporating behavior change, effects of treatment and effects of opportunistic infections. These directions include the models by Valesco-Hernandez and $\mathrm{Hsieh}^{[1]}$ who concluded that only significant reductions in the transmission probability can contain the spread of the epidemic. Such reductions could be through adoption of safer sexual practices or through reductions in viral load due to treatment. The effect of changing sexual activity on HIV prevalence was modeled by Kremer and Marcom $^{[2]}$, who found that in a one sex model, reductions in the rate of partner change by those with low sexual activity increase the average probability of HIV infection in the remaining pool of available partners. This increases prevalence among people with high activity and for highly active people disproportionately influence the spread of HIV, may increase long-run prevalence in the population as a whole. Though the models in this study allowed for changes in sexual activity, they do not allow for such differential reductions by sexual activity levels.

Levin et al. ${ }^{[3]}$ discussed mathematical models of the epidemiological and evolutionary future of the HIV epidemic. They concluded that; the AIDS epidemic has been driven primarily by transmission of the virus early in the course of the epidemic. The declines and leveling off in the incidence of new HIV infections in subpopulations at risk could largely be due to a dearth of susceptible hosts in or entering the subpopulation as opposed to the efficacy of public health measures or evolution of the virus, it will take millennia before human evolution alone significantly increase resistance to HIV/AIDS and that in populations in which HIV is relatively rare, treatment that reduces the rate of transmission of the virus can lead to substantial declines in the number of HIV-infected persons in the general population. This explanation of declines in HIV incidence in terms of shortage of susceptible is definitely incomplete without accounting for the effects of behavior change.

A model by Ying-Yen and Cooke ${ }^{[4]}$ on behavior change and treatment of core groups and its effect on the spread of HIV/AIDS showed that behavior change and treatment can eradicate the disease. The model however showed that if the treatment and behavior change levels do not reach critical values, this could lead to a "detrimental effect" on the spread of the epidemic. The detrimental effect resulted from slower progression to AIDS without sufficiently lower contact rates, resulting in the increased spread of the HIV infection. A parallel result had been derived from ${ }^{[1]}$, who said that in general, only significant reductions in the transmission probability can contain effectively the spread of the HIV epidemic. Such reduction can be brought about by condom use or through treatment.

Moghadas et al. ${ }^{[5]}$, using a model that allowed the AIDS symptomatic patients to remain sexually active, (with a rate different from that of the infective) explored the issue of condom use and found that a preventability (product of condom use efficacy and compliance by using condoms) level of at least 75 percent is required to control the HIV epidemic and concluded that the HIV epidemic could be stopped using condoms.

In Uganda studies have reported declines in numbers of sexual partners and overall declines in frequency of sexual contact as well as increases in condom use especially with non-steady or casual

Corresponding Author: F. Baryarama, Department of Mathematics, Makerere University, P.O. Box 7062, Kampala, Uganda 
partners and among the youth. Trends in percent reporting multiple partners among adults aged 15-49 years show declines among males from 39\% in 1989 to $20 \%$ in 1995 and $11 \%$ in 2000 . Corresponding rates among females were $18 \%$ in 1989 to $8 \%$ in 1995 and to $2.5 \%$ in $2000^{[6]}$. These declines by a factor of four among male and a factor of seven among females in one decade is indeed a dramatic decline in a key risk factor for HIV infection and are believed to be the main force behind the HIV prevalence declines in Uganda. In a study to examine the association between type of sexual partnership and condom use, it was found that condom use behavior is modified by partner type ${ }^{[7]}$. Sexual mixing patterns studied in Zimbabwe showed similar results ${ }^{[8]}$. Several studies have attributed declines in HIV prevalence to changes in the number of sexual partners and condom use ${ }^{[9-11]}$. The most concrete of these studies is probably the study of 174 monogamous HIV discordant couples in a population cohort in Rakai district, using data collected between November 1994 and October 1998, which gave a probability of transmission per sexual act of 0.001 and a frequency of sexual intercourse of 8.9 per month ${ }^{[12]}$. This shows that the rate of infection $\beta c$ has declined from $0.433^{[13]}$ to 0.11 , i.e. $0.001 \times 8.9 \times 12$ months. With such a decline, it is reasonable to argue for gradual behavior change models than use of constant behavioral parameters.

In this study, the derived system of equations is reduced to a generalized non-autonomous logistic differential equation $y^{\prime}(t)=y(b(t)-c(t) y)$ that is then solved.

Previous work on non-autonomous systems have assumed functions $\mathrm{b}(\mathrm{t})$ and $\mathrm{c}(\mathrm{t})$ to be positive about $\mathfrak{K}$. Nkashama $^{[14]}$ shows that if the two parameters are bounded above zero then each solution is an attractor for all the other solutions. This study extends that investigation to include the behavior of the solutions when the parameters are allowed to blow to negative infinity. This extension was necessitated by the nature of the non-autonomous logistic equation derived from a two age-group, a one-stage model for HIV/AIDS.

For the simulations, we allowed the behavior parameter to vary following an exponential decline that starts in a specified year $y_{t}$ since the onset of the epidemic.

The behavior parameter was initially assumed to be 0.433 (as used by Anderson and McLean ${ }^{[15]}$ ) until a year $y_{t}$ and allowed to drop exponentially to 0.11 (as found in a community study in Uganda ${ }^{[12]}$ ) within a 510 year period from the onset of interventions. Recruitment into adulthood is assumed to remain constant $^{[16]}$. The removal rate through progression to the AIDS stage is also assumed constant.

Model definition and reduction: Consider an HIV/AIDS model in which the number of susceptible
$\mathrm{S}(\mathrm{t})$ is recruited at a variable rate $\mathrm{q}(\mathrm{t})$ of the total population $\mathrm{N}(\mathrm{t})$. The total population is given by $\mathrm{N}(\mathrm{t})=\mathrm{S}(\mathrm{t})+\mathrm{I}(\mathrm{t})$ where $\mathrm{I}(\mathrm{t})$ is the number of infective. Hence the total population excludes the number of AIDS cases that are thus assumed removed from the population. Susceptible are removed by natural death at a constant rate $\mu$ and through infection to join the infective class at a variable rate of infection $\omega(t) I(t) / N(t)$ per susceptible. The infection is removed at a variable rate $v(t)+\mu$ where $v(t)$ is the rate of progression to AIDS. AIDS cases are removed at a variable rate $\sigma(\mathrm{t})+\mu, \sigma(\mathrm{t})$ being the rate of progression from AIDS to death. Time $t$ refers to time since the beginning of the epidemic. These assumptions lead to the following system of equations:

$$
\begin{aligned}
& \frac{d S}{d t}=q(t) N(t)-\omega(t) \frac{S(t)}{N(t)} I(t)-\mu S(t) \\
& \frac{d I}{d t}=\omega(t) \frac{S(t)}{N(t)} I(t)-(v(t)+\mu) I(t) \\
& \frac{d A}{d t}=v(t) I(t)-(\sigma(t)+\mu) A(t)
\end{aligned}
$$

Then:

$$
\frac{d N}{d t}=r(t) N(t)-v(t) I(t)
$$

where, $\frac{\mathrm{dN}}{\mathrm{dt}}=\frac{\mathrm{dS}}{\mathrm{dt}}+\frac{\mathrm{dI}}{\mathrm{dt}}$ and $\mathrm{r}(\mathrm{t})=\mathrm{q}(\mathrm{t})-\mu$ is the net growth rate of the adults in the absence of the epidemic.

Let $\phi(t)=I(t) / N(t)$ be the HIV prevalence. Then

$\frac{\mathrm{d} \varphi}{\mathrm{dt}}=\left(\mathrm{N} \frac{\mathrm{dI}}{\mathrm{dt}}-\mathrm{I} \frac{\mathrm{dN}}{\mathrm{dt}}\right) / \mathrm{N}^{2}=\frac{1}{\mathrm{~N}} \frac{\mathrm{dI}}{\mathrm{dt}}-\frac{\mathrm{I}}{\mathrm{N}} \frac{1}{\mathrm{~N}} \frac{\mathrm{dN}}{\mathrm{dt}}$.

Using

equations (2) and (4) we get

$\frac{\mathrm{d} \varphi}{\mathrm{dt}}=\frac{1}{\mathrm{~N}}\left[\omega(\mathrm{t}) \frac{\mathrm{SI}}{\mathrm{N}}-(v(\mathrm{t})+\mu) \mathrm{I}\right]-\frac{\mathrm{I}}{\mathrm{N}} \frac{1}{\mathrm{~N}}[\mathrm{r}(\mathrm{t}) \mathrm{N}(\mathrm{t})-\mathrm{v}(\mathrm{t}) \mathrm{I}]$

which on substituting with $\mathrm{S} / \mathrm{N}=1-\mathrm{I} / \mathrm{N}$ and replacing $\mathrm{I} / \mathrm{N}$ with $\phi$ gives $\mathrm{d} \phi / \mathrm{dt}=\omega(\mathrm{t}) \phi(1-\phi)-[\mathrm{v}(\mathrm{t})+\mu] \phi-\mathrm{r}(\mathrm{t}) \phi+\mathrm{v}(\mathrm{t}) \phi^{2}$ Rearranging,

factoring and noting that:

$r(t)=q(t)-\mu$ we get:

$\frac{\mathrm{d} \phi}{\mathrm{dt}}=\phi(\mathrm{a}(\mathrm{t})-\mathrm{b}(\mathrm{t}) \phi)$

where, $\mathrm{a}(\mathrm{t})=\mathrm{a}(\mathrm{t})-[\mathrm{v}(\mathrm{t})+\mathrm{q}(\mathrm{t})]$ and $\mathrm{b}(\mathrm{t})=\mathrm{w}(\mathrm{t})-\mathrm{v}(\mathrm{t})$. Equation (5) is a non-autonomous logistic equation. Later, it is shown that this equation has an explicit solution subject to certain restrictions on the variable coefficients. The steps for applying the solution applied to the HIV/AIDS 
model in equations (1-3) are discussed. In addition, when the total adult population is assumed constant (with size $\mathrm{N}_{0}$ ) equation (2) is a logistic equation given by $\quad d I / d t=I(t)[a(t)-b(t) I(t)] \quad$ where $\mathrm{a}(\mathrm{t})=\omega(\mathrm{t})-(v(\mathrm{t})+\mu)$ and $\mathrm{b}(\mathrm{t})=\omega(\mathrm{t}) / \mathrm{N}_{0}$. Hence in this case, the number of infective has an explicit solution. Assumptions of an adult constant population size have been made in HIV/AIDS models for developing countries and are intuitively meaningful in low prevalence settings.

Solution of the non-autonomous logistic equation: Let us consider the non-autonomous logistic equation:

$\frac{\mathrm{d} \phi}{\mathrm{dt}}=\phi(\mathrm{t})(\mathrm{a}(\mathrm{t})-\mathrm{b}(\mathrm{t}) \phi(\mathrm{t}))$

Suppose that $\mathrm{a}(\mathrm{t})$ and $\mathrm{b}(\mathrm{t})$ are bounded continuous functions such that:

$0<\alpha \leq \mathrm{a}(\mathrm{t}) \leq \mathrm{A}<1, \quad 0<\beta \leq \mathrm{b}(\mathrm{t}) \leq \mathrm{B}<1$

where, $\alpha, A, \beta$ and $B$ is positive real constants. Then, by the solution of (6) we mean the explicit function of $t$ that satisfies equation (6) subject to conditions (7) for all $\mathrm{t} \geq 0$.

First we note that equation (6) is a Bernoulli equation (Walter et al., 2002). Using the standard approach for solving a Bernoulli equation, we rewrite equation (6) as $d \phi^{-2} / d t-a(t) \phi^{-2}+b(t) \phi^{-22}=0$.

Multiplying by $\phi^{-2}$ gives:

$\phi^{-2-2} \mathrm{~d} \phi^{-2} / \mathrm{dt}-\mathrm{a}(\mathrm{t}) \phi^{-2-1}+\mathrm{b}(\mathrm{t})=0$

Since $\mathrm{d} \phi^{-2-1} / \mathrm{dt}=\left(-1 / \phi^{-22}\right) \mathrm{d} \phi^{-2} / \mathrm{dt}$, then:

$-\mathrm{d} \phi^{-2-1} / \mathrm{dt}-\mathrm{a}(\mathrm{t}) \phi^{-2-1}+\mathrm{b}(\mathrm{t})=0$ or $\mathrm{dy} / \mathrm{dt}+\mathrm{a}(\mathrm{t}) \mathrm{y}-\mathrm{b}(\mathrm{t})=0$,

where $\mathrm{y}=1 / \phi(\mathrm{t})$. Integrating gives

$\mathrm{y}(\mathrm{t})=\mathrm{e}^{-\mathrm{K}(\mathrm{t})}\left[\mathrm{y}_{0}+\int_{0}^{\mathrm{t}} \mathrm{b}(\mathrm{s}) \mathrm{e}^{-\mathrm{K}(\mathrm{s})} \mathrm{ds}\right]$ with $\mathrm{K}(\mathrm{t})=\int_{0}^{\mathrm{t}} \mathrm{a}(\mathrm{s}) \mathrm{ds}$.

Since $\phi(t)=1 / y(t)$, then:

$\phi(t)=e^{\mathrm{K}(\mathrm{t})}\left[\frac{1}{\phi_{0}}+\int_{0}^{\mathrm{t}} \mathrm{b}(\mathrm{s}) \mathrm{e}^{-\mathrm{K}(\mathrm{s})} \mathrm{ds}\right]^{-1}$

is the solution to the non-autonomous logistic equation (6) subject to conditions (7) provided the integrals $\int_{0}^{t} b(s) e^{-K(s)} d s$ and $K(t)=\int_{0}^{t} a(s) d s$ exist.

Extension to negative coefficients of the HIV/AIDS model: We apply this method of solving the logistic equation (5) for the HIV/AIDS model derived earlier. In the case of constant coefficients, where $a(t)$ and $b(t)$ are constants, say $a$ and $b$; equation (5) has a well known exact solution given by $\phi(t)=\left(a \phi_{0}\right) /\left[b \phi_{0}+\left(a-b \phi_{0}\right) e^{-a t}\right]$. Note that when $a>0$, then $\phi(\mathrm{t})$ increases and approaches the constant prevalence threshold $\frac{\mathrm{a}}{\mathrm{b}}$ as $\mathrm{t} \rightarrow \infty$ Whereas when a $<0, \phi(\mathrm{t})$ decreases and approaches zero as $\mathrm{t} \rightarrow \infty$.

In the general case, $\mathrm{a}(\mathrm{t})=\omega(\mathrm{t})-[\mathrm{v}(\mathrm{t})+\mathrm{q}(\mathrm{t})]$ and $\mathrm{b}(\mathrm{t})=\omega(\mathrm{t})-\mathrm{v}(\mathrm{t})$. Hence either $a(t)$ or $b(t)$ can independently reduce to zero or to negative values. We state the implications of this in the following theorem.

Theorem: If $\mathrm{a}(\mathrm{t})=\omega(\mathrm{t})-(\mathrm{v}(\mathrm{t})+\mathrm{q}(\mathrm{t})) \quad$ and $\mathrm{b}(\mathrm{t})=\omega(\mathrm{t})-\mathrm{v}(\mathrm{t})$, where $\omega(\mathrm{t}), \mathrm{v}(\mathrm{t})$ and $\mathrm{q}(\mathrm{t})$ is positive bounded functions, then the solution of equation (6) satisfies the following:

a) There exists points $t_{1}$ and $t_{2}$ such that if $f(t)=$ $\mathrm{a}(\mathrm{t}) / \mathrm{b}(\mathrm{t})$ then

(i) $\mathrm{f}\left(\mathrm{t}_{1}\right)=0$, (ii) $\mathrm{f}(\mathrm{t}) \rightarrow-\infty$ as $\mathrm{t} \rightarrow \mathrm{t}_{2}^{-}$and (iii) $\mathrm{f}(\mathrm{t}) \rightarrow+\infty$ as $\mathrm{t} \rightarrow \mathrm{t}_{2}^{+}$

b) If $\phi(0)<\mathrm{f}(0)$ then there exists a point $t_{c} \leq t_{1}$ such that $\phi\left(t_{c}\right)$ is the maximum value of $\phi(t)$, for all $\mathrm{t} \geq 0$.

c) The maximum prevalence $\phi\left(\mathrm{t}_{\mathrm{c}}\right)$ is attained when $\phi(\mathrm{t})=\mathrm{a}(\mathrm{t}) / \mathrm{b}(\mathrm{t})$ corresponding to $\mathrm{d} \phi / \mathrm{dt}=0$.

d) The minimum prevalence is determined by the lower bounds on $\omega(\mathrm{t}), \mathrm{v}(\mathrm{t})$ and $\mathrm{q}(\mathrm{t})$ and is positive.

e) There is a positive $\operatorname{arm}$ of $\mathrm{a}(\mathrm{t}) / \mathrm{b}(\mathrm{t})$, for $\mathrm{t}>\mathrm{t}_{2}$

Proof: Let $f(t)=a(t) / b(t)$. Then when $a\left(t_{1}\right)=0$ then $f\left(t_{1}\right)=0$. Let $b\left(t_{2}\right)=0$. Then $f(t)$ blows to negative infinity to the left of $t_{2}$ to positive infinity to the right of $t_{2}$. Given that $\omega(t)$ is the behavior change parameter, $v(t)$ is the rate of progression to AIDS and $q(t)$ is the net recruitment rate of susceptible then, $\omega(\mathrm{t}), \mathrm{v}(\mathrm{t}), \mathrm{q}(\mathrm{t})$ can be assumed positive. Thus $t_{1}<t_{2}$, i.e. $f(t)$ reduces to zero before it blows up to negative infinity. At time $t_{1}$ the prevalence $\phi$ has decreased since $\mathrm{d} \phi / \mathrm{dt}=-\mathrm{b}(\mathrm{t}) \phi^{2}$ when $a(t)=0$. At time $t_{2}$, the prevalence $\phi>\mathrm{a}(\mathrm{t}) / \mathrm{b}(\mathrm{t})$ since $\phi$ is none negative. Hence if $\phi(0)<\mathrm{a}(0) / \mathrm{b}(0)$, there exists $\mathrm{a} \mathrm{t}_{\mathrm{c}}<\mathrm{t}_{1}$ such that $\phi\left(\mathrm{t}_{\mathrm{c}}\right)=\mathrm{a}\left(\mathrm{t}_{\mathrm{c}}\right) / \mathrm{b}\left(\mathrm{t}_{\mathrm{c}}\right)$. Indeed the time $\mathrm{t}_{\mathrm{c}}$ corresponds to the maximum prevalence since $\phi(\mathrm{t})=\mathrm{a}(\mathrm{t}) / \mathrm{b}(\mathrm{t})$ when $\mathrm{d} \phi / \mathrm{dt}=0$. The time to peak prevalence $\mathrm{t}_{\mathrm{c}}$ can be found using numerical techniques.

Over the time interval, $\left(\mathrm{t}_{0}, \mathrm{t}_{\mathrm{C}}\right)$, the infection rate is very high with $\mathrm{v}(\mathrm{t})<(\mathrm{v}(\mathrm{t})+\mathrm{q}(\mathrm{t}))<\omega(\mathrm{t})$ and so the HIV prevalence is increasing. Over the time interval $\left(t_{c}\right.$, 
$\mathrm{t}_{1}$ ), the infection rate is still higher than the removal rate, i.e. $\omega(\mathrm{t})>\mathrm{v}(\mathrm{t})+\mathrm{q}(\mathrm{t})$ although the prevalence starts decreasing. This decrease over this time period is due to the recruitment rate compensating for the high infection rate. During the time interval $\left(\mathrm{t}_{1}, \mathrm{t}_{2}\right), v(\mathrm{t})<\omega(\mathrm{t})<(\mathrm{v}(\mathrm{t})+\mathrm{q}(\mathrm{t})), \quad$ hence $\mathrm{a}(\mathrm{t}) / \mathrm{b}(\mathrm{t})=[\omega(\mathrm{t})-(\mathrm{v}(\mathrm{t})+\mathrm{q}(\mathrm{t})] /[\omega(\mathrm{t})-\mathrm{v}(\mathrm{t})]$ becomes negative. On $t>t_{2}, \omega(t)<v(t)<(v(t)+q(t))$ making both the numerator and the denominator of $a(t) / b(t)$ negative. Hence $\mathrm{a}(\mathrm{t}) / \mathrm{b}(\mathrm{t})>0$ and as $\mathrm{t} \rightarrow \mathrm{t}_{2}^{+}, \mathrm{a}(\mathrm{t}) / \mathrm{b}(\mathrm{t})$ blows to positive infinity and approaches zero as $t \rightarrow \infty$. Figure 1 illustrates the nature of these solutions. The solid curve corresponds to $\mathrm{d} \phi / \mathrm{dt}=0$, hence it traces out the peak prevalences. It crosses $\phi(t)$ at $t_{c}$, cuts the $\mathrm{t}$-axis at $\mathrm{t}_{1}$ and is at $-\infty$ at $\mathrm{t}_{2}^{-}$.

For $\mathrm{t}>\mathrm{t}_{2}$, the solution $\phi$ has two attractors. These are the $\mathrm{t}$-axis since $\phi=0$ implies that $\mathrm{d} \phi / \mathrm{dt}=0$ and the positive branch of $a(t) / b(t)$. Though, the prevalence may never respond to the positive branch attractor a $(\mathrm{t}) / \mathrm{b}(\mathrm{t})$, the existence of this branch represents a danger signal.

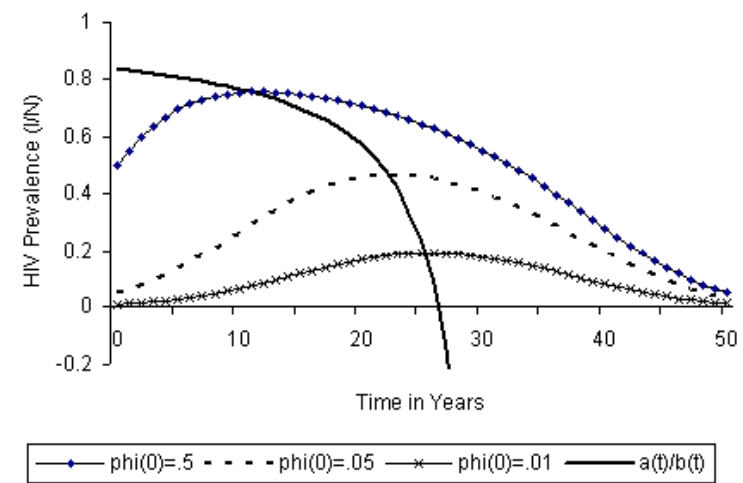

Fig. 1:Behavior of the non-autonomous logistic equation for prevalence $\phi(\mathrm{t})=\mathrm{I}(\mathrm{t}) / \mathrm{N}(\mathrm{t})$ with variable parameters

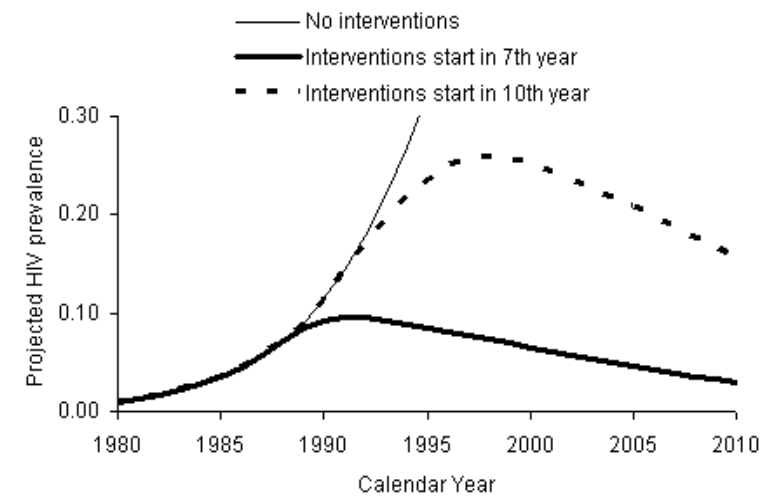

Fig. 2: Application of the model to parameter values for the case in Uganda
The positive branch of $\mathrm{t}<\mathrm{t}_{2}$ (not shown on diagram) remains as an attractor toward a resurgence in prevalence should the paramfavoralues change in favor of resurgence.

Application of the model to the HIV epidemic in Uganda: The HIV epidemic in Uganda was believed to have started in 1980 and effective interventions started in the late 1980s. Assuming behavior interventions started in 7th or 10th year and $\omega(\mathrm{t})$ reduced exponentially from 0.433 to 0.11 within 10 years.

Recruitment rate was assumed constant at $r(t)=\lambda \mathrm{e}^{-\mu_{1} a}$ where $\lambda$ is the birth rate, is the mean age of first sex and $\mu_{1}$ is the under $a$ mortality rate. Rate of progression to AIDS was fixed at 0.125 assuming 8 years from infection to the AIDS stage. This gave the scenarios shown in Fig. 2. The simulations show that the epidemic is very sensitive to assumed initial prevalence at time zero and that delaying intervention even by a couple of years may lead to a different size of the epidemic.

\section{DISCUSSION}

It has been shown that a one group, one stage HIV/AIDS model gives a non-autonomous logistic equation for the prevalence of infects whose solution was explicitly derived as an integrated solution that is often not integrable. The solution gives the HIV prevalence in terms of the model parameters and also in terms of the prevalence itself and is hence being a recurrence relation. The coefficients for the HIV/AIDS model demands the use of negative coefficients. This allowance falls outside the scope of current research on the non-autonomous logistic equation such as that of Nkashama $^{[14]}$ and Walter ${ }^{[17]}$. The solution showed that high recruitment rates would lead to the attainment of peak prevalence when the infection rate is still higher than the removal rate of infective. This finding means that declines in HIV prevalence, due to high recruitment rates, could wrongly be attributed to behavior change resulting from interventions. This has implications for evaluating HIV/AIDS programs.

One important result is that the behavior of the HIV epidemic is simply summarized in the behavior of the simple function $a(t) / b(t)=[w(t)-v((t)+q(t))] /[w(t)-$ $v(t)]$. It is important to note the role played by the recruitment rate $\mathrm{q}(\mathrm{t})$ in shortening the duration from the onset of the epidemic to the attainment of peak HIV prevalence. Simply populations with high recruitment rates of susceptibility attain the peak prevalence before the rate of transmission has reduced to levels equal to the rate of removal of ineffective by a couple of years (up to about seven years if initial prevalence had reached $5 \%$ before the commencement of a substantial response). 
A survey of existing literature in Uganda on parameter values ${ }^{[16]}$ showed that big variations had been documented of the behavior change parameters and there is evidence of little variation in the rate of progression and recruitment rates. When the parameters were applied, the model showed that the peak prevalence is sensitive to the assumed initial prevalence and that the timing of the onset of interventions determines the epidemic size. High peak prevalence's suggest that interventions started rather late when prevalence rates were already high.

\section{ACKNOWLEDGEMENT}

The authors would like to thank NUFU for the financial support towards the publication of this article and also to the anonymous referees for their valuable comments.

\section{REFERENCES}

1. Velasco-Hernandez, J.X. and Y. Hsieh, 1994. Modelling the effect of treatment and behavior change in HIV transmission dynamics. J. Math. Biol., 32: 233-249.

2. Kemer, M. and C. Marcom, 1996. The effect of changing sexual activity on HIV prevalence. Math. Biosc., 151: 99-122.

3. Levin, B.R., J.J. Bull and F.M. Stewart, 2001. Epidemiology, Evolution and Future of the HIV/AIDS Pandemic. Emerg. Infect. Dis., 7: 505511.

4. Ying-Yen H. and K. Cooke, 2000. Behavior change and treatment of core groups: its effect on the spread of HIV/AIDS. IMA J. Math. Appl. Med. Biol., 17:213-241.

5. Moghadas, S.M., A.B. Gumel, R.G. McLeod and R. Gordon, 2003. Could the condoms stop the AIDS epidemic? J. Theor. Med., 5: 171-181.

6. UNAIDS/Uganda, 2000. Uganda Epidemiological Fact Sheet on HIV/AIDS and Sexually Transmitted Diseases, Geneva: UNAIDS; DHS 1995, 2000/2001.
7. Macaluso, M., M.J. Demand, L.M. Artz and E.W. Hook, 2000. Partner type and condom use. AIDS, 14: 537-546.

8. Gregson, S., C.A. Nyamukapa, G.P. Garnett and R.M. Anderson, (2002). Sexual patterns and sex differentials in teenage exposure to HIV infection in rural Zimbabwe. Lacent, 359: 1896-903.

9. Konde-Lule, J.K., N.K. Sewankambo and M. Morris, 1997. Adolescent sexual networking and HIV transmission in rural Uganda. Health Transition Rev., 7: 89-100.

10. Mulder, D., A. Nunn, A. Kamali and J. KengeyaKayondo, 1995. Decreasing HIV-1 seroprevalence in young adults in rural Uganda cohort. BMJ., 311: 833- 836.

11. Ntozi, J.P.M. and F.E. Ahimbisibwe, 1999. Some factors in the decline of AIDS in Uganda. The Continuing African HIV/AIDS Epidemic, pp: 93107.

12. Gray, R.H., M.J. Wawer, R. Bookmeyer, N.K. Sewankambo, D. Serwadda, D. and F. WabwireMangen, 2001. Probability of HIV-1 transmission per coital act in monogamous, heterosexual, HIV1-discordant couples in Rakai, Uganda. Lacent, 357: 1149-53.

13. Mugisha, J.Y.T. and L.S. Luboobi, 2000. The endemicity of HIV/AIDS in a three-age structured population. Intern. J. Mgt and Syst., 16: 125-136.

14. Nkashama, M.N., 2000. Dynamics of logistic equations with non-autonomous bounded coefficients. EJDE., 2: 1-8.

15. Anderson, R.M. and A.R. McLean, 1988. Possible demographic consequences of AIDS in developing countries. Nature, 332: 228-234.

16. Uganda Bureau of Statistics, (UBOS), 2001. Uganda Demographic and health survey 20002001.

17. Walter, W., 1998. Ordinary Differential Equations. Springer-Verlang, NewYork. 